\title{
CONHECIMENTO SEM VALOR?
}

\author{
KNOWLEDGE Without VALUE?
}

\author{
FELIPE Rocha L. SANTOS \\ Instituto de Investigaciones Filosóficas, Universidad Nacional Autónoma de México - UNAM, MÉXICO \\ frls.ba@gmail.com
}

\begin{abstract}
The value problem is the problem that arises from the following reasoning: if both the knowledge and mere true belief are equally useful, then for what reason knowledge is more valuable than mere true belief. Despite being formulated initially in Plato's Meno dialogue, the value problem seems to have received little attention since. In contemporary epistemology, the value problem became central, requiring that any good theory of knowledge should be able to explain the value of knowledge in order to be a good theory of knowledge. Recently, new demands to the value of problem arise, demanding that it should be explained not only the reason why knowledge is more valuable, but also the reason why knowledge has final value. In this paper, two answers to the value problem that have been made recently are analyzed, namely the reliabilist solution and the virtue epistemology solution, and I will conclude that both solutions fail to explain the final value of knowledge.
\end{abstract}

Keywords: Virtue epistemology • value problem • reliabilism • final value

RECEIVED: 06/11/2017

ACCEPTED: 27/04/2018

\section{Introdução}

O objetivo deste artigo é analisar duas respostas contemporâneas ao problema do valor do conhecimento, a saber, a resposta confiabilista e a resposta da epistemologia das virtudes. Apesar de ambas as respostas serem satisfatórias se considerarmos apenas o problema do valor como aparece em Platão, elas são insatisfatórias quando consideramos as demandas recentes ao problema do valor. O problema do valor do conhecimento é um problema clássico da epistemologia que aparece pela primeira vez no diálogo Meno, de Platão (97a-d). Neste diálogo, Sócrates compara dois sujeitos, um que sabe o caminho para Larissa e outro que acredita que sabe o caminho, mas não tem conhecimento (apesar de ter a crença verdadeira sobre o caminho para Larissa). Ambos, segundo Sócrates, parecem ser bons informantes sobre o caminho para Larissa e seriam bem-sucedidos se decidissem ir para esta cidade. Desse modo, parece certo dizer que a crença verdadeira é tão útil quanto conhecimento. Mas essa conclusão não parece agradar, de modo que Meno então pergunta a Sócrates sobre qual seria a razão de o conhecimento ser tido como muito mais valioso do que a crença verdadeira. De fato, tomamos o conhecimento como algo valioso e desejável 
ao contrário da mera opinião sobre as coisas. Assim, o problema do valor do conhecimento como aparece em Meno pode ser formulado da seguinte maneira: Por que o conhecimento é mais valioso que a mera crença verdadeira?

Essa questão sempre esteve presente na epistemologia, mas diferentemente de outros problemas centrais da epistemologia, como o estudo sobre natureza do conhecimento ou os problemas céticos sobre se é possível ou não possuir conhecimento, o problema do valor não foi muito discutido entre os filósofos como os demais tópicos da epistemologia foram. Curiosamente, em certo sentido, todos os problemas em epistemologia dependem do problema do valor, visto que se não fosse a nossa intuição de que o conhecimento é de fato um estado epistêmico valioso e importante, não haveria tanta dedicação em se responder aos céticos ou se tentar definir a natureza do conhecimento.

Na epistemologia contemporânea, ao menos nos últimos 20 anos, o problema do valor tem recebido uma atenção um pouco maior, ${ }^{1}$ de modo que os filósofos têm buscado não só explicar adequadamente a natureza do conhecimento como também tem buscado explicar por que razões o conhecimento é valioso. Kvanvig, por exemplo, diz que uma boa teoria do conhecimento deve explicar não só a natureza do conhecimento como ser ao menos logicamente consistente com uma teoria sobre o valor do conhecimento (Kvanvig 2003, pp.5-6). Assim, argumenta Kvanvig, se uma teoria do conhecimento não faz um bom trabalho explicando o valor do conhecimento, então isso conta contra a explicação sobre a natureza do conhecimento. E se uma teoria é capaz de explicar adequadamente o valor do conhecimento, então isso conta a favor da teoria em relação a sua explicação sobre a natureza do conhecimento. Desse modo, uma boa teoria do conhecimento deve ser uma boa teoria sobre o valor do conhecimento.

A primeira resposta ao problema do valor é dada pelo próprio Sócrates a Meno. A resposta que Sócrates oferece a Meno é através de uma analogia com as estátuas de Daedalus. Sócrates responde o seguinte:

SOCRATES: Possuir uma das obras desse <escultor>, que seja solta, não vale grande coisa, como < possuir> um escravo fujão; com efeito, ela não permanece no lugar. Encadeada porém vale muito, pois muito belas são as obras. Mas a que propósito digo essas coisas? A propósito das opiniões que são verdadeiras. Pois também as opiniões que são verdadeiras, por tanto tempo quanto permaneçam, são uma bela coisa e produzem todos os bens. Só que não se dispõem a ficar muito tempo, mas fogem da alma do homem, de modo que não são de muito valor, até que alguém as encadeie por um cálculo de causa. E isso, amigo Meno, é a reminiscência, como foi acordado entre nós nas coisas < ditas> anteriormente. E quando são encadeadas, em primeiro lugar, tornam-se ciências, em segundo lugar, estáveis. E é por isso que a ciência é de mais valor que a opinião correta, e é pelo encadeamento que a ciência difere da opinião correta. (Platão, 98a) 
Se isto está correto, o conhecimento é estável enquanto a mera crença verdadeira não é. É fácil perder a confiança que se tem em uma mera crença verdadeira, quando por exemplo, se desconfia que o caminho a Larissa pode ser o caminho incorreto, enquanto que aquele que possui conhecimento mantém a confiança pois sabe que por mais estranho que pareça ser o caminho a Larissa, este é o caminho que leva à cidade. Entretanto, a resposta de Sócrates parece não ser muito explicativa e significativa. Kvanvig escreve que parece ser claro que é fácil esquecer-se de coisas que sabemos. O esquecimento faz parte da nossa natureza cognitiva. Ou seja, "conhecimento, assim como crença verdadeira, pode ser perdido" (Kvanvig 2003, p.13). Além disso, Kvanvig recorda que Sócrates afirma, logo após dar sua resposta, que sua resposta não é baseada em nenhum conhecimento seguro sobre a diferença. A analogia usada por Sócrates foi somente para destacar que existe uma diferença entre conhecimento e crença verdadeira. ${ }^{2}$

O problema assim parece persistir. Qual o valor do conhecimento? Por que consideramos o conhecimento algo valioso? Antes de prosseguir, é importante notar que essas perguntas podem ser interpretadas das mais diversas maneiras. Uma das formas de se entender estas questões é interpretá-las como se fossem perguntas sobre o conceito de conhecimento, ou seja: por que o conceito de conhecimento é valioso? Essa pergunta é diferente da pergunta a respeito do valor do conhecimento que aparece em Meno, pois é uma pergunta sobre por qual razão nós, como seres humanos, precisamos do conceito de conhecimento em nossas vidas.

Alguns filósofos ${ }^{3}$ respondem à questão sobre a importância do conceito do conhecimento afirmando que o conceito de conhecimento é valioso porque sinaliza fontes de boas informações e possui um papel importante na nossa vida, visto que somos seres sociais que usam e compartilham informações o tempo todo. Outros ${ }^{4}$ argumentam que o propósito do conhecimento é mostrar quando um agente tem direito de não precisar continuar investigando um assunto. Responder sobre o valor e a importância do conceito de conhecimento em nossa vida parece não ser algo problemático, mas este tipo de resposta não contribui em nada para a resposta ao problema do valor como aparece em Platão: por que o conhecimento é mais valioso do que a mera crença verdadeira, visto que aparentemente, ambos são igualmente úteis e servem igualmente para o mesmo fim? Como explicar este valor extra que o conhecimento possui, em relação a meras crenças verdadeiras?

\section{Confiabilismo e o valor do conhecimento}

O confiabilismo é uma teoria do conhecimento que se tornou bastante influente e com um número grande de adeptos na epistemologia contemporânea. Entretanto, recentemente vem sofrendo uma série de críticas, centradas no problema do valor, 
onde argumenta-se que o confiabilismo é incapaz de explicar o valor do conhecimento e portanto, não é uma boa teoria do conhecimento. Nesta seção veremos a crítica feita ao confiabilismo e a sua resposta ao problema do valor.

O confiabilismo é a teoria que diz que um sujeito $S$ sabe que $p$ se e somente se (1) $p$ é verdadeira, (2) $S$ acredita que $p$ é verdadeira, (3) a crença de $S$ de que $p$ foi produzida através de um processo confiável e (4) uma cláusula anti-Gettier é adequadamente satisfeita (Goldman e Olsson 2009, p.22). Em resumo, conhecimento é toda crença verdadeira que é formada por um processo confiável. As críticas ao confiabilismo no que diz respeito ao problema do valor não são voltadas à clausula (4), mas sim, especificamente, à cláusula (3). Isso porque um confiabilista poderia dizer que o fato do conhecimento ter sido formado por um processo confiável o torna mais valioso que uma mera crença verdadeira, visto que processos confiáveis produzem crenças verdadeiras em sua grande maioria das vezes. Dessa forma, nesta discussão sobre o problema do valor e o confiabilismo, consideraremos apenas o confiabilismo simples (ou seja, que envolve apenas as cláusulas 1-3), dado que se os argumentos apresentados são bem-sucedidos, então atinge toda teoria de cunho confiabilista que afirma que o valor extra do conhecimento é adquirido por causa do processo confiável.

O principal argumento contra o confiabilismo e teorias de conhecimento que afirmam que o conhecimento possui valor por causa do processo confiável formador de crenças ficou conhecido na literatura como swamping argument ${ }^{5}$ (SWA). Este argumento foi defendido por diversos filósofos em versões muito similares, como Jones (1997), Kvanvig (2003), Swinburne (1999), Riggs (2002) e Zagzebski (2003). O argumento afirma que o processo de formação de crença não transmite valor ao produto final, no caso, a crença verdadeira. Apresentarei aqui a versão de Zagzebski do argumento, por ser a versão mais ilustrativa e discutida na literatura. Zagzebski utiliza uma analogia com uma máquina de espresso para justificar seu argumento:

Uma máquina de espresso confiável é boa porque o espresso é bom. Uma torneira que pinga água que é confiável não é boa porque ter água pingando não é bom. O bom do produto torna a confiabilidade da fonte que o produz bom, mas a confiabilidade da fonte não dá ao produto por isso nenhum impulso adicional de valor. O líquido neste copo não é melhorado pelo fato de que se ele vem de uma máquina de café expresso confiável. Se o espresso tem um bom sabor, não faz diferença se ele vem de uma máquina não confiável. [...] Se a crença é verdadeira, não faz diferença se ela vem de uma fonte de produção de crença não confiável. (Zagzebski 2003, p.13) ${ }^{6}$

Segundo este raciocínio, é o sabor do espresso que realmente importa e por isso, não faz diferença se aquele espresso específico foi produzido por uma máquina confiável ou não, mas apenas se aquele espresso específico possui um bom sabor. O espresso não ganha um sabor extra, adicional, por conta da confiabilidade da 
máquina que o produziu. Assim, o mesmo vale para o conhecimento: o que importa é a verdade da crença e por isso, não faz diferença se a crença é ou não produzida por um processo confiável. A crença não ganha um valor extra, não se torna mais verdadeira por ter sido produzida por um processo confiável. O SWA pode ser formalizado da seguinte maneira:

(S1) Conhecimento é igual a crença verdadeira produzida de modo confiável (confiabilismo simples).

(S2) Se uma dada crença é verdadeira, seu valor não aumentará por conta do fato de que foi produzida de modo confiável.

(S3) Portanto: o conhecimento não é mais valioso que uma crença verdadeira produzida de modo não confiável. ${ }^{7}$

A conclusão deste argumento é bastante contraintuitiva, visto que nos parece que o conhecimento não é mais valioso que a mera crença verdadeira. Desse modo, para que a intuição de que o conhecimento é mais valioso do que a mera crença não seja descartada, muitos decidem negar a primeira premissa (S1), o que envolve negar o confiabilismo como teoria do conhecimento. ${ }^{8}$

É importante notar que o argumento parece só funcionar se considerarmos não apenas o confiabilismo, mas o confiabilismo somado ao veritismo. Isso porque como Zagzebski coloca, o que importa é o sabor do café, assim como o que importa no final das contas é a verdade da crença. O veritismo é a tese que diz que o que importa no final das contas é apenas a crença verdadeira (Goldman e Olsson 2009, p.24). Se de fato o que importa no final de tudo é a verdade da crença, então o veritismo somado ao confiabilismo (premissas S1 e S2) nos leva a conclusão contraintuitiva de que o conhecimento não é mais valioso que a mera crença verdadeira formada de modo não confiável.

Olsson (2007) nota que desse modo, o SWA também funciona para teorias do conhecimento internalistas que são combinadas com o veritismo, ou seja, teorias internalistas onde a justificação tem como valor apenas indicar a verdade. Assim, Olsson descreve a seguinte objeção feita por Swinburne (1999, p.58) baseada no SWA que pode ser usada contra estas teorias internalistas:

Agora, claramente é uma boa coisa que nossas crenças satisfação ao critério de justificação, pelo fato de que isso significa que elas serão provavelmente verdadeiras. Mas, se uma dada crença minha é verdadeira, eu não consigo ver que, de algum modo vale mais por ter satisfeita o critério justificacionalista. Enquanto a crença é verdadeira, o fato de que crenças justificadas são usualmente verdadeiras não parece tornar a crença de algo modo algo que vale mais a pena possuir. (Swinburne apud Olsson 2007, p.344)

Ao que parece, qualquer teoria do conhecimento que afirma que o que importa ao final das contas é apenas a verdade (veritismo) e que afirma que o valor extra 
do conhecimento se encontra em uma terceira condição como a justificação ou a confiabilidade do processo está susceptível a argumentos similares ao SWA.

Goldman e Olsson apresentam uma solução confiabilista para o problema em questão, chamada de "solução da probabilidade condicional" (conditional probabilty solution - CPS). De acordo com a CPS, uma crença verdadeira formada de modo confiável é mais valiosa do que uma mera crença verdadeira porque a primeira possui uma propriedade epistêmica valiosa que a mera crença verdadeira não possui, a saber, a propriedade de que seja provável que o mesmo processo produza mais crenças verdadeiras do que crenças falsas no futuro. E essa probabilidade alta de se produzir no futuro mais crenças verdadeiras (de um tipo semelhante) "é uma condicional maior em $S$ saber que $p$ do que a condicional em $S$ meramente acreditar verdadeiramente que $p$ " (Goldman e Olsson 2009, p.28). Utilizando a analogia com a máquina de espresso novamente, a ideia por trás da CPS é que se a máquina de espresso produz hoje um bom espresso e a máquina continua a minha disposição amanhã, então amanhã será alta a chance de ela produzir novamente um bom espresso. Goldman e Olsson afirmam que "a confiabilidade da produção de um bom copo de espresso de fato eleva ou aumenta a probabilidade de um bom copo de espresso subsequente. Esse aumento de probabilidade é uma propriedade valiosa de se ter" (Goldman e Olsson 2009, p.28).

É importante notar que essa solução não busca negar nem a primeira premissa (S1), que é a premissa confiabilista, nem a segunda premissa (S2), que afirma que o valor da crença verdadeira não aumentará pelo fato de ter sido produzida de modo confiável. O que o argumento nega é a inferência de (S1) e (S2) para a conclusão (S3). O que o argumento demonstra é que o conhecimento pode sim ser mais valioso que a mera crença verdadeira mesmo se a crença em questão não se torna mais valiosa ao se tornar conhecimento. Olsson escreve que:

Isso é o caso porque o estado de conhecimento pode ser mais valioso do que o estado de uma mera crença verdadeira: o estado de conhecimento é também um estado de aquisição confiável, de modo que o é valioso não só porque é um indicador da verdade da crença então adquirida mas também como indicativo da produção de mais crenças verdadeiras (de um tipo similar) no futuro; ou seja, as crenças verdadeiras resultantes da reaplicação do método confiável em questão. Esta é a razão pela qual conhecimento é mais valioso do que a mera crença verdadeira, mesmo se a verdade de ambas as premissas utilizadas no swamping argument são aceitas. (Olsson 2011, p.176)

É importante notar uma distinção entre o que está por trás da CPS e do SWA. Os defensores do SWA aceitam uma premissa que está implícita no argumento, a saber, de que o problema do valor do conhecimento diz respeito apenas ao valor da crença específica que é produto do processo formador de crenças. Ou seja, o objeto do valor é um produto final específico, uma instância de uma crença verdadeira. 
Por isso que a analogia com o espresso funciona. De fato, se temos dois copos de espresso a nossa frente, sendo que os dois possuem o mesmo sabor, não faz diferença se um foi produzido por uma máquina confiável e o outro não. Os dois são bons. Assim como se temos duas pessoas diferentes que possuem uma determinada crença verdadeira, como a crença verdadeira sobre o caminho para Larissa, e ambas utilizam essa crença para chegar a Larissa e são bem-sucedidos nisso, não faz diferença se uma foi produzida de modo confiável e a outra não. Saber que a crença foi produzida de modo confiável não a torna mais verdadeira.

Entretanto, Goldman e Olsson estão se referindo não ao valor do produto final, mas sim, ao valor de um estado de coisas específico, ao valor do estado de conhecimento. $\mathrm{O}$ valor de se conhecer é diferente do valor de meramente acreditar, isso porque o processo confiável faz parte do estado de coisas que torna uma pessoa um conhecedor e que produz conhecimento. Percival (2003, p.38) afirma que a premissa de que conhecimento é mais valioso que a crença verdadeira é uma premissa bastante atrativa, porém, de certo modo, bastante obscura também. Isso porque o conteúdo dessa premissa não é muito claro e, ao que parece, quando dizemos que o conhecimento é mais valioso que a crença verdadeira estamos querendo dizer que, para todo agente racional $x$ e proposições $p, x$ prefere saber que $p$ a meramente acreditar verdadeiramente que $p$. E se essa leitura é o caso, então o confiabilismo pode explicar sem sérias dificuldades o valor do conhecimento em relação a mera crença verdadeira.

A principal ideia contida na CPS é que um estado cognitivo também é um estado de aquisição de confiabilidade e, deste modo, é importante porque, de um lado, é um indicador da verdade da crença produzida e, por outro lado, implica que esse mesmo processo produzirá mais crenças verdadeiras do mesmo tipo quando for novamente utilizado. Assim, a probabilidade de se produzir crenças verdadeiras do mesmo tipo futuramente é uma condicional maior no conhecimento confiabilista do que na mera crença verdadeira. Isso explica, para os defensores da CPS, porque o conhecimento é mais valioso do que a mera crença verdadeira.

Para explicar como o conhecimento ganha valor do processo confiável, Goldman e Olsson afirmam que a probabilidade do processo produzir mais crenças verdadeiras dependem de quatro regularidades empíricas: não-exclusividade, o acesso entretemporal, a aprendizagem e a generalidade. Eles explicam estas quatro regularidades empíricas do seguinte modo:

[...] suponha que $S$ sabe que $p$. De acordo com a definição confiabilista de conhecimento, existe um método confiável $M$ que foi invocado por $S$ de modo a produzir a crença de $S$ que $p$. Pela não-exclusividade, é provável que o mesmo tipo de problema surja novamente para $S$ no futuro. Pelo acesso entretemporal, o método $M$ estará disponível para $S$ quando isso ocorrer. Pela assunção de aprendizado, $S$ provavelmente irá utilizar $M$ novamente nesta 
ocasião. E pela generalidade, é mais provável que $M$ será confiável para solucionar também este problema futuro similar. Dado que $M$ é confiável, esta nova aplicação de $M$ muito provavelmente resultara em uma nova crença verdadeira. (Goldman e Olsson 2009, p.29) ${ }^{9}$

Quando uma destas condições não for satisfeita, então o conhecimento produzido em questão não tem valor. Assim, para a solução confiabilista, há casos em que temos conhecimento, mas este conhecimento específico não tem valor porque uma das regularidades empíricas falhou. Isso não é problema para o confiabilismo nem para a CPS, visto que a alegação dos defensores da CPS é que o estado de coisas ou o estado cognitivo de conhecimento é mais valioso do que o estado de meramente acreditar verdadeiramente e não que o objeto "crença verdadeira" produzida confiavelmente é mais valioso que o objeto "crença verdadeira" produzida por sorte. Assim, Olsson alega que "a afirmação de que o conhecimento é mais valioso do que a mera crença verdadeira é uma afirmação defensível no sentido em que esta afirmação é verdadeira mesmo que existam casos especiais nos quais o conhecimento falha em alcançar este valor distintivo" (Olsson 2011, p.176)

Essa solução não agrada alguns. Kvanvig, por exemplo, escreve o seguinte contra a CPS:

Essa resposta, entretanto, falha em agarrar com o que é central no Swamping Problem. Como nós vimos, quando os controles relevantes encontram-se no lugar, deveríamos esperar, sempre e necessariamente, que o conhecimento seja uma característica de aumento de valor do estado da crença verdadeira, não somente uma característica de quando a pessoa irá provavelmente usar o mesmo método no futuro e o mundo não mudou tornando o que foi confiável no passado algo que não é mais. Para descobrir o valor especial do conhecimento, temos que controlar para as interações por valores fora da esfera puramente cognitiva, mas uma vez que fazemos, devemos descobrir que o conhecimento é especial. E não é somente especial quando o futuro se assemelha ao passado e quando as pessoas mantêm suas disposições através do tempo sobre como descobrir sobre como o mundo é. (Kvanvig 2010, p.101)

A discordância entre Kvanvig e os defensores da CPS encontra-se em como interpretar o problema do valor. Devemos interpretar o problema do valor como a pergunta sobre porque o conhecimento é necessariamente sempre mais valioso que a mera crença verdadeira ou como a pergunta sobre porque em geral preferimos o conhecimento à mera crença verdadeira? Goldman e Olsson notam que filósofos como Swinburne (1999, p.64), Williamson (2000, p.79) e Percival (2003, p.38) aceitam a segunda interpretação, ou seja, a de que o conhecimento é, em geral, mais valioso do que a mera crença verdadeira. Sobre essa interpretação mais fraca, Goldman e Olsson escrevem o seguinte: 


\begin{abstract}
Ainda assim, está longe de ser claro que o nosso pensamento pré-sistemático sobre o assunto exige que o conhecimento seja sempre mais valioso do que a mera crença verdadeira. A maioria das generalizações que aceitamos são, indiscutivelmente, de um tipo "típico" em vez de um tipo "absoluto". O dinheiro é uma coisa valiosa para ter, mas ainda assim, as pessoas ricas são, por vezes assassinadas por causa de sua riqueza; então para estes, o dinheiro foi realmente algo ruim. Pássaros voam, contudo, aves com penas cobertas de óleo não; e assim por diante. As generalizações que fazemos em nossas vidas diárias não são generalizações universais no sentido de lógica de predicados, mas alegações genéricas elásticas que podem sobreviver a um número limitado de contraexemplos. Se for assim, por que a nossa afirmação de que o conhecimento é mais valioso do que mera crença verdadeira seria diferente? (Goldman e Olsson 2009, p.31)
\end{abstract}

Se esta é a interpretação correta do problema do valor, então o confiabilismo não é atingido pelo SWA e se mostra capaz de explicar o valor do conhecimento. Segundo o confiabilismo, o conhecimento é atualmente mais valioso que a mera crença verdadeira, em oposição a ser mais valioso do que a mera crença verdadeira em todos os mundos possíveis e ainda assim, no mundo atual, não é o caso que crenças específicas tidas como conhecimento sejam sempre mais valiosas que meras crenças verdadeiras que não são consideradas conhecimento. De qualquer modo, pode-se dizer que o estado cognitivo de conhecimento é mais valioso que o da mera crença verdadeira sendo que este valor é um valor instrumental. O valor instrumental é o valor contido em elementos que servem para algum fim, como por exemplo, o dinheiro, que possui valor instrumental pois é um meio para algum outro fim. No caso da solução confiabilista, o estado cognitivo de conhecimento é um meio para se produzir com frequência crenças verdadeiras, e por isso, o valor do conhecimento é, neste caso, instrumental. ${ }^{10}$

De certo modo, podemos dizer que a resposta confiabilista soluciona o problema do valor, a depender de como interpretamos o problema. Mas filósofos como Kvanvig e Pritchard afirmam que o problema do valor não deve ser interpretado apenas como a pergunta sobre porque o conhecimento é mais importante que a mera crença verdadeira. Pritchard afirma que o problema do valor que deve ser solucionado pelas teorias do conhecimento é na verdade, um conjunto de três problemas: o problema primário, secundário e terciário do valor (Pritchard 2010, pp.5-8). Pritchard assim diz que o problema que surge em Meno é o problema primário do valor, que é o problema que envolve explicar por qual razão o conhecimento é mais valioso que a crença verdadeira. E como visto, a discussão sobre o SWA e o confiabilismo é uma discussão que diz respeito a este problema primário, ainda que existam divergências sobre qual é o objeto do valor.

O problema secundário do valor vai além do problema primário, sendo uma consequência natural do mesmo. O problema secundário é o problema que envolve ex- 
plicar por qual razão o conhecimento é mais valioso do que qualquer subconjunto de elementos que o constitui e também mais valioso do que o valor de suas partes tomados em separado. Como visto na discussão sobre o SWA, o confiabilismo simples diz que conhecimento é a crença verdadeira formada por um processo confiável. Mas muitos confiabilistas adotam uma quarta cláusula à definição de conhecimento, como cláusulas anti-Gettier. Ora, se o que dá valor ao conhecimento é o processo confiável (ou qualquer outra terceira cláusula como a justificação, garantia, etc), então parece que a quarta cláusula que algumas teorias defendem não são necessárias, visto que o que queremos é o estado cognitivo que é valioso sendo que aquilo que se aproxima de conhecimento (como a crença verdadeira formada confiavelmente) satisfaria o nosso desejo. Isto tornaria desnecessária qualquer quarta cláusula anti-Gettier extra.

O problema secundário do valor busca mostrar que o conhecimento possui um valor distinto de suas subpartes combinadas ou tomadas de modo independentes. Mas ainda assim, o problema secundário que parece exigir que o conhecimento tenha um valor distinto mostra que a diferença de valor entre o conhecimento e suas partes é uma diferença de grau apenas e não de tipo de valor. Desse modo, o que é chamado por Pritchard de problema terciário do valor é o problema que demanda mais do que os problemas primários e secundários. É o problema que envolve explicar por qual razão o conhecimento possui um valor distinto, ou seja, um valor não só maior em grau do que suas subpartes, mas um valor diferente - final - que suas subpartes não possuem.

A resposta confiabilista ao problema do valor pode explicar o problema primário, mas a depender da teoria confiabilista, não responde ao problema secundário e também não responde ao problema terciário, pois não explica a diferença do valor do conhecimento como uma diferença de tipo. Para o confiabilismo, o conhecimento é apenas instrumentalmente mais valioso sendo que não possui valor final, tanto que, como Goldman e Olsson afirmam, não é o caso que toda instância de conhecimento possui mais valor do que a mera crença verdadeira (Goldman e Olsson 2009, p.30). Se esta nova demanda do problema do valor está correta, então o confiabilismo falha em solucionar o problema do valor, pois não explica porque o conhecimento possui valor final.

\section{Epistemologia das virtudes e o valor final}

Greco (2010) propõe uma solução baseada em sua versão da epistemologia das virtudes que, segundo ele, é capaz de responder ao problema primário, secundário e terciário do valor. A epistemologia das virtudes diz que conhecimento é um tipo de sucesso por causa das habilidades cognitivas. Ou seja, conhecimento é uma realização cognitiva. E isso porque é um tipo de sucesso através da agência virtuosa (através do 
uso das virtudes intelectuais). A epistemologia das virtudes é uma teoria de base confiabilista. Uma virtude intelectual, uma habilidade cognitiva, deve ser confiável para que possa produzir com sucesso crenças verdadeiras. Dessa forma, pode-se dizer que se as respostas confiabilistas (como a CPS) estão de algum modo corretas, mesmo que incompletas, a epistemologia das virtudes herda tais soluções, visto que uma virtude intelectual em boa ordem produzirá futuramente muito mais crenças verdadeiras do que habilidades cognitivas não confiáveis. Por ser uma teoria do conhecimento de cunho confiabilista e com foco no agente e não em processos ou na crença como objeto de investigação, pode-se dizer que a epistemologia das virtudes já explica o valor instrumental do conhecimento.

De acordo com a epistemologia das virtudes, em casos de conhecimento o agente possui a crença verdadeira porque ele é intelectualmente capaz e exerceu suas habilidades cognitivas da forma correta. Greco então utiliza-se de Aristóteles para apresentar sua solução:

Na Ética a Nicômaco, Aristóteles faz uma distinção entre (a) alcançar algum fim por sorte ou acidente, e (b) a realização do e através do exercício das habilidades (ou virtudes). É apenas o último tipo de ação, Aristóteles argumenta, que é tanto intrinsecamente valioso e constitutivo de florescimento humano. "Bem humano", escreve ele, "acaba por ser atividade da alma exibindo excelência". Nessa discussão, Aristóteles está claramente preocupado com a virtude intelectual, bem como com a virtude moral: sua posição é de que o exercício bem-sucedido de uma de virtudes intelectuais é intrinsecamente bom e constitutivo de florescimento humano. (Greco 2010, pp.97-8)

O exercício das virtudes intelectuais é tanto valioso intrinsicamente - ou seja, possui valor independentemente das relações com objetos externos - como é constitutivo da prosperidade humana. Realizações cognitivas são exercícios de virtudes intelectuais. Tais realizações cognitivas resultam em conhecimento e por isso, conhecimento é intrinsecamente valioso e constitutivo da prosperidade humana. Greco explica como a epistemologia das virtudes então é capaz de solucionar o problema terciário, mostrando que o conhecimento possui valor final e distinto do valor instrumental:

Podemos agora ver que a solução proposta respeita todas as suposições e responde todas as perguntas. [...] O conhecimento é um tipo de sucesso por habilidade, e em geral, sucesso por habilidade é intrinsecamente valioso e constitutivo de florescimento humano, que também é intrinsecamente valioso. Além disso, tanto o sucesso por habilidade e desenvolvimento humano possuem valor "final", ou seja, valor como um fim em si mesmos, independentemente de qualquer valor instrumental que eles também possam ter. Portanto, o conhecimento tem um valor acima do valor prático da verdadeira crença. (Greco 2010, p.99) 
De acordo com esta solução, o conhecimento possui então valor final. O valor final é um tipo de valor que é fim em si mesmo, em oposição ao valor instrumental, que é um meio para algum fim. O dinheiro, como já exemplificado, possui valor instrumental. Mas como conhecimento é o sucesso por causa de realizações cognitivas, e realizações cognitivas como o exercício de virtudes intelectuais possuem valor em si mesmo, então o conhecimento também possui valor final.

$\mathrm{O}$ fato de possuir valor final mostra que conhecimento possui um valor maior que o valor prático da crença verdadeira (problema primário do valor) e também um tipo de valor que não é apenas um valor superior por questão de graus, mas um tipo distinto de valor (problema terciário do valor). Essa solução também explica o problema secundário do valor, que envolve explicar por qual razão o conhecimento é mais valioso do que qualquer subconjunto de elementos que o constitui e também mais valioso do que o valor de suas partes tomados em separado. Dado que o conhecimento é um tipo de sucesso por causa das habilidades cognitiva, podemos dizer que sucesso por causa das habilidades é mais valioso do que o sucesso sem habilidade (por pura sorte) ou habilidade sem sucesso. Greco escreve:

Em particular, a crença verdadeira produzida virtuosamente é mais valiosa do que tanto a crença verdadeira que não é virtuosa e a crença virtuosa que não é verdadeira. Nenhum dos subconjuntos é intrinsecamente valioso, ou constitutivos do que possui valor intrínseco ou final, da forma como o conhecimento é. (Greco 2010, p.99)

Além disso, Greco observa que o sucesso por causa das habilidades é mais valioso do que ações bem-sucedidas e com habilidades, mas que não é bem-sucedida por causa da habilidade. Por exemplo, uma corrida em que os atletas que participam correm demonstrando claramente suas habilidades como atletas. Mas a atleta vencedora vence não porque foi a melhor, mas porque todos os outros competidores no dia anterior comeram algo que não os fizeram bem, prejudicando totalmente as suas respectivas performances (exceto a vencedora, que não teve nenhum problema de saúde). Nesse caso, a atleta foi bem-sucedida, pois venceu, e demonstrou suas habilidades, mas ela não venceu por causa de suas habilidades. Assim, o sucesso por causa das habilidades é mais valioso do que o sucesso com habilidades, mas não por causa das habilidades. O mesmo vale para casos de conhecimento que são sucessos por causa das habilidades cognitivas e casos estilo-Gettier em que é possível existir o sucesso com habilidade, mas que não é conhecimento porque não é por causa das habilidades (Greco 2010, p.99).

A solução da epistemologia das virtudes de Greco ao problema do valor pode ser resumida da seguinte forma:

(P1) Realizações são sucessos por causa da habilidade (tese da Realização) 
(P2) Conhecimento é um sucesso cognitivo por causa das habilidades cognitivas (Epistemologia das Virtudes)

(C1) Portanto, conhecimento é uma realização cognitiva (Tese do Conhecimento como realização);

(P3) Realizações possuem valor final (Tese do Valor das Realizações);

(C2) Portanto, conhecimento possui valor final.

A ideia por trás da solução de Greco é que se de fato realizações possuem valor final então conhecimento, por ser considerado realizações cognitivas, também possuem valor final. E realizações possuem este tipo de valor porque demonstram o exercício da agência de um sujeito no mundo, de suas virtudes epistêmicas, o que é constitutivo de uma vida humana rica e próspera. Esta solução parece bastante promissora, porém, não é uma solução livre de problemas. É preciso analisar quais tipos de realizações, se todas, possuem valor final, e também se é possível considerar que tudo o que vale para realizações em geral valem também para realizações cognitivas. Se existem realizações que não possuem valor final ou se realizações cognitivas possuem um valor distinto de realizações em geral, então a solução apresentada por Greco falha em responder ao problema terciário do valor.

A solução da epistemologia das virtudes aparentemente responde ao problema do valor em todas as suas formas. Entretanto, uma investigação mais detalhada faz surgir algumas perguntas que precisam ser respondidas. É uma solução que precisa de mais qualificação, visto que parece que algumas realizações não parecem ser tão valiosas. Por exemplo, se eu preciso ir na cozinha beber um copo de água, basta eu me levantar, caminhar até a cozinha, pegar o copo d'agua e beber. Foi uma realização por causa de minhas habilidades, mas parece ser algo muito fácil ou de pouco valor. O mesmo vale para a formação de crenças: basta eu estar de olhos abertos agora para perceber e formar a crença verdadeira de que há um computador em minha frente. Parece fácil demais para ser considerado como uma realização ou algo com um valor distintivo ou um valor superior.

Algumas realizações também parecem poder possuir valor negativo, ao invés de um valor neutro. Por exemplo, um cientista pode desenvolver uma nova bactéria super-resistente e mortal capaz de ser utilizada como arma de destruição em massa, causando a morte de milhões de pessoas. É, de fato, uma realização, mas a princípio parece ser o caso que esta realização não é uma realização que possui valor positivo. Não desejamos que isso ocorra e se ocorresse, seria pouco provável que tal cientista se tornasse mundialmente reconhecido e valorizado por ter conquistado tal façanha.

Uma forma de responder essa objeção é afirmar que o que possui valor final são as realizações qua realizações, independente das demais coisas. Assim, a realização do cientista em questão possui sim um valor final (mesmo que se usada pra algo maléfico), visto que podemos por exemplo supor que esta mesma realização poderia ser 
usada para eliminar uma raça de extraterrestre inimigos que invadiram a terra para simplesmente dizimar os humanos. Esse cientista, diante da mesma realização, seria reconhecido e valorizado mundialmente por ter salvo a raça humana do extermínio ao criar sua nova bactéria mortal. Desse modo, é coerente dizer que o que possui valor final são as realizações qua realizações, e não o uso ou objetivo das realizações quando a mesma ocorre.

Mas ainda assim, resta outra objeção: a objeção das realizações fáceis. Segundo a epistemologia das virtudes, realizações por causa de habilidades são quaisquer sucessos por conta das habilidades envolvidas. Levantar a mão para fazer uma pergunta é um ato de sucesso por conta das habilidades. Olhar para a mesa, ver um copo de água na mesa e formar a crença verdadeira de que há um copo de água na mesa é um ato de sucesso por causa das habilidades cognitivas. Mas são sucessos fáceis, quase que triviais e aparentemente, de pouco valor. Claro, podemos supor a diferença entre uma pessoa que ficou cega com um ano de idade de depois de adulta, implantou uma tecnologia que a permite ver novamente, sendo que a primeira coisa que ela faz é olhar para a mesa e com muita dificuldade, dada a tecnologia em questão, formar a crença verdadeira de que há um copo de água na mesa. Para essa pessoa, essa será uma realização que possuirá grande valor e será lembrada pro resto da vida. Mas isso porque para essa pessoa, essa não é uma realização trivial. Algumas realizações parecem possuir um grau maior de valor do que realizações muito fáceis ou triviais. Como responder a esta objeção?

Essa objeção diz que se definirmos "realizações" como "sucesso por causa de habilidades" então seremos forçados a assumir como realizações certos tipos de sucesso que não são intuitivamente realizações, como por exemplo, simplesmente olhar para a frente ou levantar o braço para fazer uma pergunta. Podemos supor, por exemplo, que ao vermos um amigo nosso conquistar seu diploma de Doutor em Filosofia, iremos parabenizá-lo pela conquista, por essa grande realização. Mas acredito que nunca veremos uma situação com amigos em um jantar em que, ao ouvir o amigo nos pedir para lhe passar o sal, iremos lhe parabenizar pela grande conquista, pela grande realização de ter visto que há um pote de sal na mesa e por nos ter passado o mesmo. Segundo Pritchard, a razão pela qual não consideramos intuitivamente esse tipo de sucesso fácil como realizações de fato se dá porque nossa concepção intuitiva de realização envolve tanto a aplicação de um nível significante de habilidade como também envolve superar obstáculos significantes para atingir o sucesso (Pritchard 2010, p.68). E no caso de realizações fáceis, não temos presente nenhum destes dois elementos presentes.

Atingir o sucesso pode ser fácil para algumas pessoas como atletas de alto nível. Uma atleta olímpica como a atleta brasileira Fabiana Murer, medalhista e recordista em salto com vara, pode facilmente saltar uma altura de 2 metros, pois isso para ela é fácil. Não é uma realização que aparentemente envolve a superação de grandes 
ou significantes obstáculos. Mas nós consideramos esse tipo de ação uma realização porque mesmo sendo fácil para ela, sabemos que é preciso superar muitas dificuldades e obstáculos para atingir este nível de facilidade ao se realizar certos saltos. Assim, esse tipo de ação, mesmo fácil para um sujeito específico, não deixa de ser considerado por nós uma realização, uma conquista, por causa de suas habilidades. O mesmo podemos dizer para o caso de uma pessoa sofreu um acidente e ficou paralítico por muito tempo, mas que agora, depois de muita fisioterapia, consegue lentamente se mover e andar. Essa ação não é resultado de muitas habilidades, mas consideramos uma conquista porque envolve grande superação de obstáculo. Assim, parece que realizações estão muito mais relacionadas com superação de obstáculos e dificuldades do que da presença de habilidades em si, mesmo nas ações fáceis para experts como atletas de alto nível, visto que consideramos as superações de obstáculos ou dificuldade algo que ocorre durante o aprendizado, treino e aperfeiçoamento.

Sendo realizações por habilidades cognitivas em geral realizações fáceis, será então que devemos concluir que considerando esse sentido de realizações como superação de obstáculos, não existem realizações por causa de habilidades cognitivas? Não necessariamente. Por exemplo, um matemático, através do uso do raciocínio, memória e dedução pode conseguir solucionar problemas complexos, ou seja, ser bem-sucedido por causa de suas habilidades cognitivas, e este sucesso é facilmente considerado uma realização pois envolve superação de dificuldades e obstáculos. Assim, se esta definição está correta, a consequência é que alguns casos de conhecimento são realizações, sucesso por causa das habilidades cognitivas e por causa de, em certo sentido, envolver a superação de obstáculos e dificuldades, e em outros casos de conhecimento, temos apenas o sucesso por causa de habilidades cognitivas, mas não realizações nesse sentido de superação de obstáculos e dificuldades. Pritchard realiza a seguinte distinção entre as teses a respeito das realizações:

(Tese Fraca das Realizações) Realizações são sucessos por causa da habilidade.

(Tese Forte das Realizações) Realizações são sucessos que ocorrem por causa das habilidades onde o sucesso em questão tanto envolve a superação de obstáculos significativos ou o exercício de um nível significante de habilidade. (Pritchard 2010, p.70)

A tese fraca sobre realizações é uma tese inclusiva, de modo que considera realização qualquer sucesso por causa das habilidades cognitivas do agente, sucesso esse que expressa o poder de agência do sujeito. Essa é a tese adotada por Greco em sua epistemologia das virtudes. Já a tese forte sobre realizações não considera casos em que há sucesso fácil como realizações de fato. A solução para quem adota a tese fraca de se dizer que realizações qua realizações possuem seu valor final, não importando se são realizações fracas ou fortes, não se mantém, segundo Pritchard. Ele escreve: 


\begin{abstract}
A fim de ver isso, precisamos apenas observar que as "realizações" fáceis em questão poderiam muito bem ser de grande valor, todas as coisas consideradas, e ainda teriam igualmente demonstrado o ponto pretendido. Talvez, por exemplo, há um grande valor prático que se mostra ao levantar o braço neste contexto (por exemplo, alguém se identifica como o vencedor do prêmio, e por isso recebe um prémio que teriam sido perdido por falta de identificação). Ainda assim, não há nenhuma tentação de supor que o simples ato de levantar um braço em circunstâncias normais, qua realizações fracas, é de valor final. A questão, então, não é que essas "realizações" são, em si, ausentes de valor simpliciter, mas mais especificamente, que elas carecem de valor final. (Pritchard 2010, p.71)
\end{abstract}

Para Pritchard, realizações fracas não possuem valor final. Apenas as realizações fortes é que possuem valor final, que é o tipo de valor que se busca atribuir ao conhecimento em geral. ${ }^{11}$ Outra distinção importante que deve ser feita para se analisar melhor a solução de que realizações possuem valor final é a distinção entre os tipos de habilidades, havendo assim a distinção entre habilidades básicas e habilidades não-básicas (skills). A diferença entre estes dois tipos de habilidades é a seguinte:

Habilidades básicas - Não requer instruções. Não é aprendida. Pode ser aprimorada. Não é possível realizar erros voluntários ao usá-las. As habilidades cognitivas (ou virtudes intelectuais) são habilidades básicas.

Habilidades não-básicas - É aprendida. Exige algum tipo de instrução para se executá-la. É possível voluntariamente cometer erros.

Com esta distinção pode-se perceber que apesar de ser possível haver realizações no sentido forte através do uso de habilidades cognitivas, habilidades estas que produzem conhecimento, em geral isso não ocorre. Em geral, o sucesso por causa de habilidades cognitivas são realizações no sentido fraco, pois habilidades cognitivas são habilidades básicas, onde não temos controle direto sobre elas e onde grande parte das realizações são realizações fáceis. Desse modo, mesmo que realizações por causa de habilidades (não básicas) possua valor final, o mesmo não vale para realizações por causa de habilidades básicas. Assim, a inferência (C1), (P3) e (C2) do argumento de Greco falha, de modo que não se pode dizer que conhecimento possui valor final.

\title{
4. Considerações Finais
}

O problema do valor, como originalmente aparece em Platão, não parece ser um problema de difícil solução. A solução confiabilista, que interpreta o problema como apenas um problema sobre por que razões em geral o conhecimento é mais valioso 
que a mera crença verdadeira, é uma solução satisfatória, pois mostra o valor instrumental que o conhecimento possui. Entretanto, novas exigências e formas de se interpretar o problema do valor foram surgindo, criando um novo desafio para as teorias do conhecimento, que é o de se explicar porque o conhecimento possui valor final. A solução mais promissora até então era a solução da epistemologia das virtudes, que, entretanto, falha em explicar o valor final do conhecimento, visto que mesmo que realizações possuam valor final, o mesmo não pode ser dito para realizações por causa de habilidades cognitivas. Acredito que o problema do valor parte de um falso pressuposto $^{12}$ - que o conhecimento possui valor final - e que a melhor solução seria aquela que demonstrasse isto. Por conta disso, me parece certo que todas as soluções para o problema do valor final do conhecimento não serão bem-sucedidas.

\section{Referências}

Bradford, G. 2015. Achievements. Oxford: Oxford University Press.

Craig, E. 1990. Knowledge and the State of Nature: An Essay in Conceptual Synthesis. Oxford: Clarendon Press.

Goldman, A.; Olsson, E. J. 2009. Reliabilism and the Value of Knowledge. In: A. Haddock; A. Millar; D. Pritchard (eds.) Epistemic Value. Oxford: Oxford University Press, pp.19-41.

Greco, J. 2010. Achieving Knowledge: A Virtue-theoretic Account of Epistemic Normativity. Cambridge: Cambridge University Press.

Jones, W. E. 1997. Why do we value knowledge? American Philosophical Quarterly 34(4): 423-39.

Kelp, C. 2013. How To Motivate Anti-Luck Virtue Epistemology. Grazer Philosophische Studien 88: 119-33.

Kvanvig, J. 2003. The Value of Knowledge and the Pursuit of Understanding. Cambridge: Cambridge University Press.

- 2010. The swamping problem redux: Pith and gist. In: A. Haddock; A. Millar; D. H. Pritchard (eds.) Social epistemology, pp.89-111. Oxford: Oxford University Press.

Olsson, E. J. 2007. Reliabilism, Stability, and the Value of Knowledge. American Philosophical Quarterly 44: 343-55.

- 2008. Knowledge, truth, and bullshit: Reflections on Frankfurt. Midwest Studies in Philosophy XXXII: 94-110.

- 2011. Reply to Kvanvig on the Swamping Problem. Social Epistemology: A Journal of Knowledge, Culture and Policy 25(2): 173-82.

Olsson, E. J.; Jonsson, M. L. 2011. Kinds of Learning and the Likelihood of Future True Beliefs: Reply to Jäger on Reliabilism and the Value Problem. Theoria 77: 214-22.

Percival, P. 2003. The Pursuit of Epistemic Good. Metaphilosophy 34: 29-47.

Platão. 2001. Mênon. Traduzido por Maura Iglésias. Editora PUC Rio. Edições Loyola: São Paulo, Brasil.

Pritchard, D. 2010. Knowledge and Understanding. In: D. H. Pritchard; A. Millar; A. Haddock (eds.) The Nature and Value of Knowledge: Three Investigations. Oxford: Oxford University Press, pp.5-88. 
2012. Anti-Luck Virtue Epistemology. Journal of Philosophy 109: 247-79.

Riggs, W. D. 2002. Reliability and the Value of Knowledge. Philosophy and Phenomenological Research 64: 79-96.

- 2008. The Value Turn in Epistemology. In: V. Hendricks; D. Pritchard (eds.) New Waves in Epistemology. Aldershot: Ashgate, pp.300-23.

Swinburne, R. 1999. Providence and the Problem of Evil. Oxford: Oxford University Press.

Williamson, T. 2000. Knowledge and its Limits. Oxford: Oxford University Press.

Zagzebski, L. 2003. The Search for the Source of Epistemic Good. Metaphilosophy 34: 12-28.

\section{Notas}

${ }^{1}$ Riggs (2008) sugere que a epistemologia recente sofreu um value turn de modo que tem deixado de ser uma epistemologia que se foca na crença (belief-driven epistemology) para se tornar cada vez mais uma epistemologia centrada no valor (value-driven epistemology).

${ }^{2}$ Williamson (2000) procura demonstrar que há algo além de uma mera analogia na resposta de Sócrates. Um dos pontos levantados por Williamson é que é importante considerar o aspecto temporal envolvido ao problema do valor. Ao apresentar parte de seu argumento, Williamson escreve que "the present argument concerns only delayed impact, not action at the 'next' instant. We do not value knowledge more than true belief for instant gratification." (2000, p.79). Se Williamson está correto no que diz respeito a gratificações instantâneas, nas ações que ocorrem no exato momento em que se adquire conhecimento não parece haver uma diferença real de valor entre conhecimento e mera crença verdadeira.

${ }^{3}$ Cf. Craig (1990), Greco (2010) e Pritchard (2012).

${ }^{4}$ Cf. Kelp (2013).

${ }^{5}$ Uma possível tradução para "swamping argument" seria "argumento da inundação". Mas acredito que esta tradução não é precisa e por conta disso resolvi manter o termo em inglês.

${ }^{6}$ Todas as traduções neste artigo são traduções minhas.

${ }^{7}$ Esta formulação é apresentada em Goldman e Olsson (2009, p.23).

${ }^{8}$ Neste caso, estamos falando do confiabilismo que afirma que o valor é adquirido por conta do processo confiável. Uma possível resposta confiabilista a esse problema é dizer que o valor é adquirido por conta da cláusula extra anti-Gettier que foi satisfeita.

${ }^{9}$ Segundo Olsson $(2011$, n.5), todas as quatro condições devem ser interpretadas de modo externalista, ou seja, não é necessário haver algum tipo de acesso ou consciência de tais regularidades por parte do agente.

${ }^{10}$ Há uma outra resposta confiabilista ao problema do valor, dada por Olsson, mas que não será analisada aqui pelo fato de ter como consequência as mesmas consequências da CPS. Segundo a solução de Olsson, a crença verdadeira adquirida confiavelmente é mais valiosa que a mera crença verdadeira porque é uma crença estável. E estabilidade é algo valioso porque promove ações bem-sucedidas no futuro. Para mais detalhes, ver Olsson $(2007 ; 2008)$.

${ }^{11}$ Para uma discussão mais detalhada sobre realizações como superação de obstáculos e dificuldades, ver Bradford (2015).

${ }^{12}$ De fato, como todo este debate demonstra, a intuição de que o conhecimento possui algum valor extra ao valor puramente instrumental é muito forte. Mas a ausência de respostas satisfatórias, em especial em relação ao valor final, sugere que é possível que todo 
este problema esteja baseado na premissa falsa de que de fato o conhecimento possui valor final. Sem dúvida é necessário uma investigação mais aprofundada e melhores argumentos para justificar esta minha crença, trabalho este que farei nas minhas investigações seguintes.

\section{Agradecimentos}

Este artigo foi produzido durante o meu estágio pós-doutoral no Instituto de Investigaciones Filosóficas da Universidade Nacional Autónoma de México, UNAM. 